\title{
Variación diacrónica de las formas de tratamiento en el español de Chile. Una propuesta de estudio
}

\author{
Diachronic variation of address forms \\ in Chilean Spanish. A research proposal
}

\section{MARCELA J. L. RIVADENEIRA VALENZUELA ${ }^{1}$, ALEJANDRA M. CONTRERAS GUTIÉRREZ ${ }^{2}$, MANUEL E. CONTRERAS SEITZ ${ }^{3}$}

\author{
${ }^{1}$ Universidad Católica de Temuco \\ Correo electrónico: mrivadeneira@uct.cl \\ ${ }^{2}$ Universidad Católica de Temuco \\ Correo electrónico: alejandra.contreras@uct.cl \\ ${ }^{3}$ Universidad Austral de Chile \\ Correo electrónico: manuelcontreras@uach.cl
}

El presente trabajo es una propuesta de estudio de corte variacionista en el que se busca dar cuenta del desarrollo histórico de las formas de tratamiento en el español de Chile en documentos producidos en los siglos XVI, XVII y XVIII. La metodología incluye un análisis integral en el cual confluyen factores pragmáticos, discursivos y culturales. Se trata de la primera vez que se plantea una investigación diacrónica en el español de Chile, cuyo objetivo es describir y analizar procesos de cambio lingüístico a través de una muestra significativa ${ }^{1}$. Como puntapié inicial, presentamos aquí el planteamiento de estudio y un análisis preliminar de documentos del siglo XviI en el que se abordan aspectos de variación en los planos morfosintáctico y pragmático-discursivo.

Palabras clave: formas de tratamiento, variación lingüística, diacronía, español de Chile

The present study is a variationist proposal on the historical development of address forms in Chilean Spanish in documents from the XVI, XVII and XvIII centuries. The methodology includes an integral analysis of pragmatic, discourse and cultural factors. This is the first diachronic research on Chilean Spanish whose goal is to describe and analyze the processes involved in linguistic change through consistent empirical data. To begin with, along with the research proposal a preliminary analysis on the use of XvII century address forms and their relationship to grammatical and discourse-pragmatic variables is presented.

Key words: address forms, linguistic variation, diachrony, Chilean Spanish

\footnotetext{
$1 \quad$ El presente trabajo forma parte del proyecto de investigación Fondecyt $\mathrm{N}^{\circ} 1171031$ titulado "Variación diacrónica de las formas de tratamiento en el espańol de Chile: siglos XVI a XIX".
} 


\section{INTRODUCCIÓN}

\subsection{Las formas de tratamiento}

El presente trabajo se basa en una propuesta de investigación enmarcada dentro del ámbito de las formas de tratamiento, entendiéndose estas como la manera o modo en que nos dirigimos hacia un interlocutor, representado por la segunda persona gramatical de singular o plural. En general, las formas de tratamiento presentan una rica variación lingüística, ya que

Dentro del conjunto de los signos lingüísticos [estas] pertenecen a los que más estrechamente se vinculan a la cultura del comportamiento de una sociedad y a las actitudes de los hablantes hacia los interlocutores en las respectivas situaciones comunicativas. De ahí que tiendan a variar en todas las dimensiones de la lengua (Hummel, Kluge \& Vázquez Laslop 2010: 15).

Las formas de tratamiento han sido ampliamente estudiadas en español, tanto desde enfoques sincrónicos como diacrónicos y en relación a diversos aspectos que podríamos catalogar en función de la perspectiva adoptada en su estudio: filológicos, pragmáticos, sociolingüísticos o sociopragmáticos, de los cuales resumimos brevemente los tres primeros a continuación (Medina Morales 2010: 24-31):

El enfoque filológico se caracteriza por una descripción no sistemática de los hechos, aunque se reconocen los tratamientos como un rasgo social y por ende se extraen conclusiones sobre condicionamientos sociales y algunas veces incluso estilísticos. No obstante, no se analiza necesariamente la relación entre los factores lingüísticos y estos últimos. Destacan en este ámbito los trabajos de St. Clair Sloan (1922), Pla Cárceles (1923), Wilson (1940) y Lapesa (1970a,b), autores que dan cuenta de los valores de tú, vos, vuestra merced (y sus derivaciones vuesa merced, vuesarcé, vusted), él y ella (como pronombres áureos poco deferentes) en gramáticas (el Tesoro de Covarrubias), diccionarios y textos literarios (El Quijote, Cantar de Mio Cid, las comedias de Tirso, de Lope o de Calderón).

El enfoque pragmático se basa en la propuesta del trabajo clásico de Brown y Gilman (1960) sobre la semántica del poder y la solidaridad, el que ha sido constantemente retomado y mejorado por numerosos autores, especialmente en cuanto a la metodología, la que contempla el uso de cuestionarios. En Hispanoamérica este enfoque es aunado con la perspectiva dialectológica, de fuerte arraigo (Henríquez Ureña 1921; Rona 1964, 1967), dando como resultado la generación de importantes proyectos de estudio (como el Proyecto de estudio coordinado de la norma lingüística culta de las principales ciudades de Iberoamérica y de la Península Ibérica). Si bien la propuesta de poder y solidaridad no puede aplicarse a todas las lenguas y culturas del mundo, con relaciones sociales más complejas (Michele de Oliveira 2010), es innegable la vigencia de este postulado teórico para explicar la situación actual e histórica de las formas de tratamiento en diversas comunidades del mundo. 
Por último, el enfoque sociolingüístico en el estudio de las formas de tratamiento ha sido uno de los más fructíferos, dado el interés en los distintos niveles de variación que presentan estas, especialmente al comparar el actual sistema tripartito del español americano con el bipartito peninsular para la segunda persona del singular.

Tabla 1. Formas de tratamiento en el mundo hispánico

\begin{tabular}{|c|c|c|}
\hline & 2a persona singular & 2a persona plural \\
\hline \multirow{3}{*}{ Español americano } & Tú & \\
& Vos & Ustedes \\
\hline \multirow{2}{*}{ Español peninsular } & Usted & Vosotros \\
& Tú & Ustedes \\
\hline
\end{tabular}

Esta variación en el sistema pronominal es sin duda uno de los aspectos más relevantes en la distinción de las dos normas de español. El voseo americano "tiene una importante difusión en América, y es además -creo que puede afirmarse con rotundidad-el fenómeno morfológico de mayor relevancia entre los que caracterizan el español americano" (Saralegui 1986: 277). Entre los trabajos de corte sociolingüístico de esta línea destacan especialmente los desarrollados para la variedad dialectal rioplatense, desde una perspectiva tanto sincrónica como diacrónica. El énfasis, además de considerar el componente cuantitativo (en frecuencias de uso del rasgo lingüístico) está en explicar cualitativamente el funcionamiento del paradigma según factores como la relación entre los interlocutores y el contexto comunicativo, a partir de lo cual han surgido interesantes propuestas de corte sociopragmático (García 1994; Morín Rodríguez 2001).

En estrecha relación con las dos últimas perspectivas, la línea disciplinar que seguimos en este trabajo parte desde una arista variacionista en el que además confluyen factores pragmáticos, discursivos y culturales bajo el alero de un objetivo general, en el que se busca dar cuenta del desarrollo histórico de las formas de tratamiento en el espańol de Chile en documentos producidos en los siglos XVI, XVII y XVIII. Se trata de la primera vez que se plantea una investigación diacrónica, con miras a profundizar en los procesos de cambio lingüístico en el español de Chile a través de una muestra documental significativa. Como puntapié inicial, en este trabajo presentamos la propuesta de estudio y un análisis preliminar de documentos del siglo xvi en el que se abordan aspectos de variación en los planos morfosintáctico y pragmático-discursivo.

A continuación examinaremos algunos aspectos relevantes sobre el sistema de tratamiento en Hispanoamérica, comenzando por uno de los rasgos más distintivos dentro del paradigma de la segunda persona, el voseo. 


\section{ESTADO DEL ARTE}

\subsection{El voseo}

El voseo se define en la actualidad como el empleo de flexión verbal de segunda persona de singular o de plural (modificado) con el pronombre vos y, alternativamente, a la combinación entre este plural y el pronombre tú (Rivadeneira y Clua 2011).

La historia del voseo se remonta al latín del siglo iv, época en la que se empleaba la forma pronominal vos con función de segunda persona plural, como símbolo de respeto, inicialmente en el trato con el emperador (Carricaburo 1997; Lapesa 1970; Solé 1970). Se distinguen diversas etapas en el desarrollo del voseo. Goza de prestigio hasta mediados del siglo XVI, cuando se produce un desbalance en el paradigma pronominal de la segunda persona con recurrentes confusiones entre los sistemas verbales de voseo y tuteo para dirigirse indistintamente a la segunda persona del singular y plural (Pla Cárceles 1923; Garrido 1992; Rini 1996):

El peligro de confusión entre el tú y el vos alcanzaba nada menos que a diez tiempos verbales... Ante riesgo tan grave la conciencia lingüística de las gentes cultas reaccionó aferrándose a las formas con -d-, todavía utilizables y prestigiosas; las mantuvo en la lengua escrita y frenó con ellas en el habla la generalización de las formas contractas. Cuando en la Península desaparecieron vos tomás, vos tenés y paralelamente vos tenias, vos cantabas, vos eras, vos fuesses, no hizo falta conservar por más tiempo las formas esdrújulas plenas, cuya -d- era minoritaria en el conjunto de frecuencias efectivas dentro de la conjugación (Lapesa 1968:530).

A nivel social, el empleo cada vez más extendido de voseo en los estratos bajos provoca la desarticulación del tratamiento de vos con valor de respeto, siendo reemplazado por el sintagma nominal vuestra merced, introducido de pleno en el siglo XVII (Carricaburo 2004). A finales del siglo XVIII, se prohíbe el uso de voseo en la norma culta (Penny 1991), registrándose solo en escasas zonas rurales de la península (Llorente 1965; Zamora 1943). Veamos a continuación de manera general el desarrollo histórico de las formas de tratamiento en español ${ }^{2}$ :

Modificado de Penny (1991: 1152) y Rini (1996: 10-11), en Rivadeneira (2009: 43-51). 


\begin{tabular}{ccccc}
\hline & Siglo XV & Siglo XVI & Siglo XVII & Siglo XVIII \\
\hline \multirow{3}{*}{ Singular } & tú quieres & tú quieres & tú quieres & tú quieres \\
& vos queredes & & & \\
& vos querés & vos querés** & vos querés*** & \\
& vos queréis & & vuestra merced & usted quiere \\
\hline Plural & vos queredes* & vos queréis** & vosotros queréis & vosotros queréis \\
& vos querés* & vosotros queréis & quercedes & ustedes \\
& vos queréis & quieren & q*** \\
\hline
\end{tabular}

* Formas que empiezan a caer en desuso. En el caso del plural, esto ocurre hacia finales del s. xv.

** Empiezan a caer en desuso a mediados del s. Xvi.

*** Escasos registros.

**** Parte de Andalucía y las Islas Canarias.

El sistema descrito aquí corresponde a la evolución del sistema pronominal en la norma peninsular, la cual, tras la conquista de América, tuvo influencia directa sobre los virreinatos de México, Perú y las Antillas, regiones que mantenían una relación comercial sistemática con el reino de España, mientras que las zonas más alejadas y con menor contacto recibieron influjo tardío de los nuevos cambios. Este factor no deja de ser relevante, en tanto que provoca el desarrollo de sistemas de tratamiento voseantes, tuteantes y mixtos en las distintas regiones, de manera tal que los virreinatos se mantienen como zonas casi exclusivas de tuteo, mientras que el resto de regiones más alejadas desarrollan las otras dos tipologías, dependiendo del grado de contacto directo que tienen con la península (Lapesa 1968; Kany 1969; Garrido 1992; Benavides 2003), como seńala Lapesa:

La repartición geográfica parece responder a hechos culturales bien determinados: vos fue desechado en las regiones que, como México o el Perú, eran asientos de cortes virreinales con intensa vida señorial y urbana, o que, como Santo Domingo, poseían universidades influyentes; a ellas iban llegando con fuerte capacidad de difusión los usos que iban prevaleciendo en la metrópoli: en nuestro caso, el desprestigio de vos y la rehabilitación del tú. También desapareció el vos en Cuba y Puerto Rico, que siguieron dependiendo de España hasta 1898. Pero en zonas como la América Central, los llanos de Colombia y Venezuela, la sierra ecuatoriana, Chile y el Río de la Plata, que en los siglos XviI y XviII no tuvieron corte virreinal importante y cuyas condiciones de vida eran menos urbanas, perduró el vos con diversa intensidad, aunque no en todas las formas pronominales (1970: 152-153).

Hoy en día, se observa una situación interesante en las zonas donde, históricamente, el voseo ha competido con el tuteo en los tratamientos de confianza. En efecto, mientras el uso de voseo parece establecerse en los núcleos íntimos, el tuteo parece quedar relegado a niveles 
intermedios de formalidad (RAE 2005; Hummel 2010). En Argentina, su empleo llega incluso a niveles de alta formalidad (Carricaburo 1997). No obstante, el escollo principal, desde un punto de vista investigativo, es lograr trazar la línea de desarrollo histórico de un rasgo que se vuelve característico del español americano, pero que empieza paulatinamente a desaparecer de los registros escritos, toda vez que se hace sentir el peso social de la norma lingüística peninsular, como se atestigua en el Galateo español (Gracián 1593): "Quien llamase de vos a otro, no siendo muy más calificado, le menosprecia y hace ultrage en nombralle, pues se sabe que con semejantes palabras llaman a los peones y trabajadores" y en el Arte kastellana (Correas 1627): "De vos tratamos a los criados y vasallos... Entre amigos, donde no hay gravedad ni cumplimientos, se tratan de vos".

En este sentido, el valor de intimidad que va adquiriendo el voseo desde el s. XvII en adelante complica la labor de rastreo documental, ya que su uso empieza a relegarse a los círculos de confianza, lo que significa acudir a documentos privados, tales como cartas personales. Este tipo de muestras se constituye, en una primera instancia, de la correspondencia mantenida entre los colonos espańoles y sus familiares en la península o extranjeros de otras nacionalidades que habitan en las regiones colonizadas y se comunican con parientes o personas cercanas de otras zonas americanas; en segunda instancia se presentan las cartas de criollos, es decir, hijos de padres españoles que nacen y se educan en territorio nacional y que escriben a personas dentro o fuera de Chile.

Varios estudios se han centrado en aspectos diacrónicos del sistema pronominal del español. En América, destacan particularmente los trabajos de Fontanella de Weinberg (1971, 1987, 1989, 1995-1996, 1999), Rojas Mayer (1988-1989, 1992, 1997) y Rigatuso (1986, 1988-1989, 1992, 1993) para el español de Argentina, y el de Bertolotti (2001, 2004, 2011, 2012) para Uruguay. Se han realizado, asimismo, otros estudios sobre formas de tratamiento, pero no con la misma sistematicidad: para Bolivia, Ramírez Luengo (2003); Costa Rica, Moser (2010) y Quesada Pacheco (1988, 2006, 2010); México, Vázquez Laslop (2010). En Chile, solo se registra un puñado de estudios de corte histórico, los que se sintetizan a continuación.

\subsection{Estudios diacrónicos sobre las formas de tratamiento en Chile}

Escasos son los estudios que conforman la única base de investigación sobre el desarrollo histórico del sistema de tratamiento en el español chileno ${ }^{3}$. Destaca en estos trabajos la focalización en el análisis de voseo, dado que se trata de un rasgo que es distintivo de nuestra variedad dialectal y que difiere de todas las otras variedades de voseo americano, no solo en el plano lingüístico (fonético-fonológico, morfosintáctico, pragmático-discursivo) sino que también en la dimensión social -variaciones a nivel diastrático, diatópico y diafásico

\footnotetext{
3 Omitimos un trabajo de Torrejón (2010b) titulado "El voseo en Chile: Una aproximación diacrónica", ya que se trata más bien de una revisión bibliográfica sobre el rasgo, aunque se realiza un pequeño análisis de documentos históricos, los que no son mayormente discutidos.
} 
(Rivadeneira 2009, Rivadeneira y Clua 2011, Rivadeneira 2016). Esta marcada diferencia, que se da a nivel dialectal en general, se encuentra condicionada principalmente por las particularidades geográficas de nuestro territorio y por la historia lingüística y cultural que la han determinado como zona dialectal 'exclusiva' dentro de las variedades de español (Benavides 2003, Cerny 1999).

De esta forma, en Araya (1995) se presenta un enfoque sociolingüístico sobre la variación en las formas de tratamiento en un escrito autobiográfico de la monja clarisa Úrsula Suárez (1666-1749). El texto analizado corresponde, en efecto, a una de las obras coloniales criollas más reconocidas y valoradas a nivel lingüístico, tanto por la naturalidad y espontaneidad de la escritura como por la visión sociohistórica que se puede inferir a partir de los hechos narrados por la monja (Cartagena 2002a; Rivadeneira 2009; Frago 2010; Rivadeneira 2016). Es más, se puede incluso proyectar el empleo actual de voseo a partir de los patrones morfosintácticos de Suárez, como apunta Cartagena (2001: s. f.): "[...] el actual voseo chileno está ya conformado en sus líneas básicas en los siglos XVII y XVIII".

(1) “Señor de mi alma y Dios de mi corason, ¿qué querís que haga yo?” (p. 161) "Sois muy chiquita y enferma, y no eres para monja" (p. 127)

Ahora bien, el estudio de Araya es significativo y aporta datos cuantitativos sobre la variación en los sistemas pronominales. Sin embargo, no se profundiza mayormente en relación a aspectos morfosintácticos o pragmáticos. El segundo estudio corresponde a Sweeney (2013), quien aborda el uso de voseo en documentos coloniales. Aunque la autora titula su trabajo dentro del ámbito lingüístico ("El voseo en Chile: Factores histórico-morfológicos que explican su aparición y mantenimiento"), cabe señalar que el aporte más relevante se halla en realidad en la contextualización histórica pormenorizada sobre la procedencia de los pobladores de estas tierras, aludiendo al número y la posterior influencia dialectal de los habitantes de origen castellano (y no andaluz, como se sostiene tradicionalmente). En cuestiones más lingüísticas, desafortunadamente tanto el corpus como el análisis empleado son solo exploratorios. Por último, Newall (2007) proporciona un estudio de seis obras literarias de los siglos XviII y XIx (entre las que destacan Martin Rivas y Sub-Terra) en las que analiza el uso de voseo en relación a variables lingüísticas y sociales. El autor concluye que el voseo se encuentra en declive, según queda demostrado por el análisis cuantitativo de este rasgo frente al tuteo, lo que Newall extrapola en general a 'español de Chile', aserción que debe considerarse con mayor cautela, ya que su trabajo se basa en obras ficticias, que, si bien pueden reflejar parte de la realidad lingüística, responden más a la creatividad e ingenio de sus autores: "La literatura puede reproducir estas reacciones a través del diálogo y la narración de acciones, pero están matizadas por un propósito estilístico del autor" (Díaz 2010: 28-29).

Ejemplos tomados de la edición filológica de Ferrecio y de Ramón (1984). 
En efecto, queda en evidencia la falta de una investigación que dé cuenta del desarrollo de las formas de tratamiento en el español de Chile y los procesos de variación que surgen de la mano con cambios socioculturales. De esta forma, poco se sabe sobre el periodo de cambio del vos formal al informal, de su reemplazo por vuestra merced en el ámbito de respeto y de la transformación de este en usted, pues todos los datos que se manejan hasta la fecha corresponden a documentos provenientes de otras zonas geográficas. Por otro lado, Torrejón (2010a: 419) señala que "el tuteo parece haber estado totalmente ausente de los registros públicos en los comienzos de la Colonia. Debe haber estado reducido exclusivamente al trato intrafamiliar, en el cual se dirigía a los miembros de menor estatus". No obstante, el corpus utilizado por el autor corresponde solo a once cartas que abarcan un periodo de catorce años (1551-1575). Lo mismo aplica para el caso de voseo, que Torrejón atribuye como propio de "relaciones tal vez más informales, como las de tía-sobrina" (p. 419). Al respecto, Fontanella de Weinberg (1994: s. p.) plantea para el español americano en general: "tú es la fórmula cuyo destinatario se encuentra en el polo de mínimo poder, vuestra merced expresa respeto hacia su destinatario, mientras que vos ocupa un lugar intermedio, ya que puede expresar un poder más atenuado que tú sobre el destinatario en relaciones asimétricas o solidaridad en relaciones íntimas". En su análisis de cartas privadas -obra publicada por Otte (1981) - Fontanella de Weinberg (1994) constata la supremacía del tuteo durante los siglos Xvi y XvII, hipótesis que habría que comprobar para el caso de Chile. De momento, lo único que tenemos a disposición son premisas basadas a partir de la autobiografía de Suárez (s. XVIII) e inferencias sobre el probable uso oral de la lengua, las que se extraen de las opiniones de gramáticos del siglo XIX, como concluye Torrejón (2010a: 420):

A lo largo del siglo xviII el tuteo parece haber ganado algún terreno en el tratamiento íntimo de los miembros de las clases educadas, probablemente por el contacto que tuvieron éstos con los usos de la corte virreinal limeña y con los de los funcionarios españoles encargados de la administración colonial. Entre la mayor parte de la población urbana y rural la norma debió ser el voseo, tanto en situaciones simétricas de distancia o de intimidad, como en situaciones asimétricas, en que se lo dirigía al que estaba en posición inferior en la escala de poder. Ésta fue la situación con que se enfrentó Andrés Bello (1834 y 1847) en la segunda década del siglo xix. Bello afirma que ha oído vosear "no solo a gentes de poca instrucción, sino a predicadores de alguna literatura" y que "el vicio de que hablamos, al paso que grave y vulgar, se ha hecho excesivamente común en este país” (Bello 1834: 470).

Al respecto, agrega Bello en otro comentario de su Gramática: "No debe usarse en la conversación el pronombre vos, porque si se habla con una sola persona se debe decir usted o tú según el grado de familiaridad que tengamos con ella... pero no sólo se peca contra el buen uso usando a vos en lugar de tú, sino (lo que es aún más grave y vulgar) concertándole con la segunda persona de singular de los verbos". (1951[1834]: 469, en Torrejón 1989: 547). 
Para el autor, el voseo podía ser aceptado solo en un ámbito de uso limitado: "Hai en la segunda persona pluralidad ficticia cuando se dice vos por tú, representándose como multiplicado e individuo en señal de cortesía o respeto; pero ahora no se usa este vos sino cuando se habla a Dios o a los Santos, o en ciertas piezas oficiales, donde lo pide la lei o la costumbre. Vos por vosotros es hoi puramente poético" (Bello 1883: 82), a lo que añade en el pie de página: "El vos de que se hace tanto uso en Chile en el diálogo familiar, es una vulgaridad que debe evitarse, i el construirlo con el singular de los verbos una corrupcion insoportable. Las formas del verbo que se han de construir con vos, son precisamente las mismas que se construyen con vosotros", con lo cual se puede asumir que este rasgo era generalizado en los registros íntimos hacia finales del siglo XIX.

No obstante, las nuevas reformas prescriptivas adoptadas en la norma del español de Chile después de Bello tuvieron un efecto a mediano y largo plazo en el sistema de tratamiento, específicamente en el nivel morfosintáctico: "we can now asume that voseo was employed frequently in the standard norm until Bello's educational interference in the end of the $19^{\text {th }}$ century, when vos was prohibited and tú took its place. This would be the cut-off point when verbal voseo began to spread and proliferate through the mixed modality in the standard norm, while vos became stigmatized" (Rivadeneira 2016: 96). Así, fue la modalidad verbal o mixta verbal (combinado con tú) la que proliferó más tarde en los registros informales del español chileno, mientras el valor de estigma asociado al empleo de vos se mantiene hasta nuestros días, por lo menos en cuanto a su función en contextos situacionales de agresividad (Torrejón 1986, Rivadeneira y Clua 2011). Nos referimos, pues, a un cambio lingüístico que nace en el seno de reformas sociales y que repercute sobre el sistema gramatical de la lengua. Sin embargo, la carencia de estudios diacrónicos relativos al ámbito morfosintáctico en el español de Chile no nos permite indagar mayormente sobre cómo ni cuándo comienzan a vislumbrarse dichos procesos de cambio en la norma escrita. Extrapolable esta aserción a los distintos niveles de la lengua, el ámbito histórico ha sido en general escasamente abordado en nuestro país, tal como apunta Contreras Seitz (2009a): "los estudios lingüísticos poco han ahondado en la perspectiva diacrónica de la lengua en nuestro territorio. En este sentido, aparte de las observaciones generales efectuadas por Oroz (1966) sobre la base de material literario, la mayor parte de los trabajos han sido dedicados al estudio de las cartas de Pedro de Valdivia" (p. 32). Fuera de un proyecto de estudio de tres años de duración (desde 1989 a 1991) ${ }^{5}$, señala el autor que las iniciativas enfocadas al ámbito histórico han sido desde entonces solo trabajos individuales, con lo cual ciertamente nos alejamos de otras regiones hispanohablantes en las que se han efectuado grandes proyectos de estudio que develan la historia lingüística, social y cultural de un país (Rojas 1985 y Fontanella de Weinberg 1987, Argentina; Álvarez Nazario 1991, Puerto Rico; Medina y Méndez 2011, México).

\footnotetext{
Se trata del proyecto Dinámica del cambio lingüistico en la historia del español de Santiago de Chile (Siglos XVI-XVII-XVIII), liderado por Alfredo Matus y en el que colaboraron como co-investigadores Soledad Dargham y José Luis Samaniego.
} 
En concordancia con lo anterior, es importante contar con fuentes documentales adecuadas que den cuenta no solo de los ámbitos públicos, sino también de los privados, entendiéndose estos como manifestaciones no exclusivas sino hasta cierto punto amalgamadas, en sus distintas tipologías textuales. Por ello, es necesario hacer una recopilación exhaustiva que permita generar un conjunto de documentos de consulta:

La enorme cantidad de materiales existentes para el análisis de la evolución de fenómenos léxicos y gramaticales no podrá ser aprovechada cabalmente mientras continúe en forma meramente impresa. Es imprescindible digitalizar sistemáticamente siglo por siglo dichos datos con el fin de obtener un corpus realmente representativo y analizable electrónicamente, por ejemplo, mediante programas de concordancias y de búsqueda y clasificación de estructuras sintácticas, lo que permitiría captar con gran precisión los aspectos cuantitativos de los procesos diacrónicos y fijar la base científica para su evaluación cualitativa (Cartagena 2002: 69).

En este sentido, de mucha utilidad es la creación de una matriz de rasgos como la propuesta por Contreras (2009a) para el análisis de factores sintácticos, si bien en nuestro caso nos enfocaremos con más detenimiento en el nivel gramatical de las formas de tratamiento.

\subsection{Las fuentes documentales y los ámbitos de uso 'público' y 'privado'}

Nuestra propuesta de estudio se centra en el análisis del periodo colonial en Chile, comprendido entre los siglos Xvi y xviII. Para ello, emplearemos diversas fuentes documentales, entre las que destacan los tres volúmenes de Memoria documental en textos chilenos del periodo colonial (Contreras Seitz et al. 2013). Dicha obra reúne una edición paleográfica lingüistica de fuentes manuscritas, es decir, se respetan íntegramente las características fonografemáticas de los textos.

Los documentos reunidos en Memoria documental incluyen diferentes tipologías textuales, entre las que se encuentran textos notariales, judiciales, diplomáticos, actas de cabildo, testamentos, inventarios y cartas personales. Este abanico de registros textuales permite sin duda llevar a cabo un análisis de las formas de tratamiento en relación a una variable estilística. No obstante, dadas las características históricas en el desarrollo de voseo en Hispanoamérica, se comprueba la necesidad de acudir especialmente a documentos privados, los cuales son escasos, no solo en la obra mencionada, sino en general en la mayoría de corpus diacrónicos elaborados, debido a que se trata de textos propios del ámbito cotidiano o íntimo y que por ende no son de naturaleza pública. El carácter interaccional asociado al lenguaje familiar hace de este material un elemento esencial para el estudio de las dinámicas de tratamiento:

Las cartas $[\ldots]$ constituyen una muestra excepcional, pues permiten estudiar un vasto repertorio de formas lingüísticas que pueden considerarse como 
representativas de una variedad de habla semiformal y que, pese a la forma escrita, constituyen la mayor aproximación a la variedad de español hablada por sus autores (García Mouton 1999, Oesterreicher 1996), un auténtico ejemplo de parlato scritto 'lo hablado escrito' [de Mauro 1970] (Bentivoglio 2002-2004: 230).

No obstante, cabe discutir, por un lado, lo que se tradicionalmente se considera "privado" o "público". Según Heredia (1985, citado en Contreras Seitz 2009b: 124) se pueden establecer cuatro tipologías de cartas, teniendo en cuenta variables como emisordestinatario (autoridad soberana, autoridad delegada, autoridad constituida, particular) y tipo de carta (real, oficial, particular, privada). No obstante, las tipologías pueden ser aún más complejas:

Un documento es público si es creado por una persona pública o bajo su dirección o en su nombre, es decir, si la voluntad que determina la creación del documento es pública por naturaleza. Una persona pública es una persona jurídica que desempeña funciones consideradas públicas por el sistema jurídico en el que la persona actúa y, mientras las desempeña, está revestido de algún poder soberano para ejercerla. Por contraste, un documento es privado si es creado por una persona privada o bajo su dirección o en su nombre, es decir, por una persona que desempeña funciones consideradas privadas por el sistema jurídico en el que la persona actúa (Duranti (1996:85, citado en Contreras Seitz 2009b: 124. Destacado del original).

Por otro lado, los textos de tipo judicial revisten gran importancia desde un punto de vista pragmático-discursivo, ya que se trata de documentos en los que es común la transliteración de juicios orales, en tanto se remiten al discurso referido, entendiéndose este como "un recurso lingüístico que permite a los hablantes recrear una situación discursiva, lo que se materializa mediante la reproducción de los enunciados proferidos por las voces intervinientes en la situación evocada y la reconstrucción del correspondiente contexto de enunciación (San Martín y Guerrero 2013: 260). En esta línea, para efectos de estudio, consideramos pertinente la identificación de los distintos usos de la segunda persona a través de la reproducción de situaciones de interacción.

Asimismo, se debe tener en consideración que, en el caso particular de los documentos históricos recopilados en Chile, se constata que "la mayoría de los testimonios existentes fueron puestos en tinta por quienes poseían una educación formal baja, empujados a la labor no por una ambición o plan estrictamente literario". (Contreras Seitz y Salvo 2013: 6). De hecho, la labor de escribano podía ser ejercida en general por cualquier persona que fuera: "mayor de veinticinco ańos, lego, de buena fama, leal, cristiano, reservado, de buen entendimiento, conocedor del escribir y vecino del lugar" (Pérez 1983: 42, citado en Contreras Seitz y Salvo 2013: 16). Así, sería incluso probable hallar evidencia de rasgos propios de registros más vulgares en textos supuestamente formales, pues, 
$\mathrm{Al}$ observar con detención un corpus judicial de los siglos XVI o XVII chileno, la característica más evidente que se observa es una escritura muchas veces desprolija, alejada de las exigencias propias de la diplomática y la necesaria homogenización de la forma que ésta exigía. ¿Escribanos autodidactas que aprendieron la diplomática por imitación de un documento traído desde el Perú? Probable y posiblemente sí. La caligrafía es una de las evidencias más claras de la falta de educación de quienes llegaron a Chile, ya que es el trazo lo que permite dar cuenta de la apropiación del formato y su mutabilidad que aleja el texto de la diplomática tradicional, establecida. Se aleja de la estandarización propia del oficio (Contreras Seitz y Salvo 2013: 16).

Nos referimos acá a la competencia escrita de impronta oral o lo hablado en los textos (Oesterreicher 1996, citado en Medina Morales 2005: 127), competencia que "se manifiesta cuando el autor no tiene suficiente formación cultural, aunque sepa escribir. [...] No conoce ni la variedad lingüística exigida por el género respectivo ni las reglas discursivas válidas para la estructuración del texto, [el cual] tiene construcciones y elementos que normalmente se usan en el ámbito de la conversación” (Medina Morales 2005: 127).

Dada la relevancia en la conformación de lo que sería nuestra variedad dialectal, es pertinente entonces cuestionarse sobre la incidencia del factor cultural en la formación educacional de los escribanos en Chile. Además, tratándose de nuestro objeto de estudio, sería interesante analizar los procesos de variación que fueron teniendo lugar en el plano gramatical a medida que se fueron aplicando en la escritura los cambios socioculturales acaecidos durante las distintas etapas del desarrollo histórico del español chileno.

\subsection{Sobre la formación cultural en Chile desde el siglo XVI}

Como se ha visto en las secciones anteriores de este proyecto, existe una tendencia a considerar que la pervivencia o variación en el uso de las formas de tratamiento en Chile, y del voseo específicamente, durante los siglos XVI a XVIII, se debe, entre otras cosas, a la condición político-administrativa del país durante el periodo colonial. En este sentido, el hecho de que Chile haya sido una Capitanía General alejada de los centros virreinales, conlleva que, por un lado, el contacto de los vecinos con funcionarios metropolitanos con mejor preparación cultural sea menos frecuente y que, por el otro, el desarrollo en términos económicos, sociales y culturales de la región sea más lento que el experimentado en los Virreinatos, por cuanto es indudable que por esta categoría político-administrativa Chile se presente menos permeable a los cambios que se van dando en todo ámbito de la vida social, política y cultural de las colonias. Este hecho, sumado a la afirmación de Contreras Seitz y Salvo (2013) respecto a la falta de educación de que da cuenta la caligrafía de los escribientes y a la necesidad que plantean de analizar en "futuras investigaciones" sobre manuscritos coloniales la "procedencia de quienes escriben" (p. 3), nos lleva a proponer como arista de nuestra investigación las características culturales de los escribanos y autores de misivas en 
Chile colonial y especialmente a sugerir el análisis de la formación académica que poseían estos personajes, pues nos resulta plausible la hipótesis de que el factor educacional incida en el uso y la adquisición de las normas cultas de la lengua española.

Incluida esta arista se hará necesario, entonces, atender a los lineamientos generales que poseía la educación en Chile colonial, para por medio de ella descubrir su eventual incidencia en el uso que se hace de las formas de tratamiento durante los siglos XVI a XVIII.

Sobre la enseñanza colonial chilena no es mucha la tinta que ha corrido. Pese a ello, existen obras fundamentales como las de José Toribio Medina (1905): La Instrucción pública en Chile desde sus origenes hasta la fundación de la Universidad de San Felipe, Alejandro Fuenzalida Grandón (1903): Historia del desarrollo intelectual en Chile (1541-1810), José Manuel Frontaura Arana (1892): Noticias históricas sobre las escuelas públicas de Chile a fines de la era colonial y Amanda Labarca (1939): Historia de la enseñanza en Chile, entre otras, que pueden servirnos como fuentes para nuestra investigación. Incluso, considerar la revisión de la Ratio Studiorum (plan de estudios que se aplicaba en los colegios de la Compañía de Jesús desde fines del siglo xvi hasta 1767, año de la expulsión) puede servirnos como referente en tanto que es el primer y único documento escrito que expone los métodos y contenidos que se enseñaban durante la colonia, permitiéndonos conocer de primera fuente cuáles eran los lineamientos que se seguían en la educación colonial.

Dicho esto, es interesante destacar que en todas estas obras (exceptuando la Ratio Studiorum, obviamente) los autores opinan que la enseñanza en el periodo colonial fue mediocre y desactualizada (Fuenzalida Grandón, 1903; Medina, 1905; Labarca, 1939), opinión que nos adelanta una definición de cómo pudo haber sido la formación académica de los autores de los documentos.

Por otro lado, llama la atención que uno de los aspectos que más se critica de esta educación sea la excesiva importancia que aún en pleno siglo xviII se le da al estudio del latín, teniéndosele como la causante de toda impropiedad o uso inadecuado de la lengua vernacular. Como se lee en la cita de Fuenzalida Grandón (1903):

Unidos los estudios desde su oríjen por el latin, lengua que prevalecia sin contrapeso, sufria grave detrimento el idioma nacional, que era maltratado hasta lo increible, no ya solo por la jeneración escolar sino por la misma jeneracion enseñante, aun por los mismísimos directores de los cuerpos sabios. Este rasgo de ignorancia general de los preceptos mas elementales de la gramática lo hallamos comprobado plenamente al recorrer los orijinales de los documentos de ese tiempo, i es sin duda alguna un síntoma de lo que en otras capas de la sociedad pasaba (p. 96).

Agregando luego:

La ortografía, en jeneral, de los documentos de la época está plagada de gazafatones. Es difícil encontrar páginas en que no se tropiece con errores de consideración i en que no se estropeen gentilmente todos los fueros gramaticales; de ordinario 
se enlazan palabras que debieran estar separadas, se desunen otras que debieran estar juntas et sic de coeteris. Lo que impone una doble fatiga al recorrerlos, porque amen del desciframiento de aquellos jeroglíficos debe hacerse el trabajo de restaurar la verdadera espresion, muchas veces abreviada arbitraria i torpemente, cuando no injertada con un latin bárbaro en que el mas zahorí queda en aprietos para desenredarlo (Íbid, p. 96).

Afirmaciones que, junto con otras, nos permiten lucubrar sobre una eventual correspondencia entre la formación académica de los autores de la época y el uso que hacen de las formas de tratamiento, con especial énfasis en el voseo, en tiempos en que la norma culta metropolitana da cuenta de su desprestigio, radicando en ello y en la falta de estudios que consideren esta perspectiva el interés que tenemos por incorporar el análisis de las condiciones culturales y educativas coloniales a esta investigación.

\section{Metodología}

\subsection{Sobre las fuentes documentales}

Parte de los documentos que utilizaremos para esta propuesta de estudio corresponden a la obra Memoria documental en textos chilenos del periodo colonial (Contreras Seitz et al. 2013). Este primer corpus de consulta comprende los siguientes periodos:

- Siglo xvi: 1544 al 1599 (89 textos)

- Siglo XVII: 1600-1699 (117 textos)

- Siglo XVIII: $1700-1798$ (83 textos)

Los documentos que se incluyen en los tres volúmenes han sido extraídos de los Fondos Históricos del Archivo Nacional. Para el siglo XvI, la documentación proviene principalmente de la mano de escribanos. Es decir, se trata de textos públicos (cartas de obligación, poder, pago y ventas, cargos de cuentas, cartas al rey y autoridades, testamentos, entre otros). Se encuentran, no obstante, también algunos documentos de carácter personal (cinco en total) en donde se constatan relaciones de familiaridad. En ambos casos, el origen de los autores de los documentos es peninsular.

El volumen del siglo XviI también consta de autores de proveniencia peninsular, pero en este periodo se añade además un número importante de criollos (escribanos y autores particulares). Los documentos son, igualmente, públicos (cartas al rey, solicitudes y peticiones a autoridades, cartas de obligación, testamentos, traspasos de tierras e inventarios de bienes), a excepción de tres cartas personales.

Por último, los documentos del siglo xviII dan cuenta de diversos autores de origen peninsular y criollos provenientes de Perú. Los autores chilenos, por su parte, son numerosos. 
Los documentos incluyen autorizaciones, pagos de derechos, inventarios de bienes, ventas de tierras, testamentos, cartas de liquidación, cartas al rey y peticiones a autoridades, entre muchos otros. Los textos privados que se encuentran en este volumen son solo cuatro.

Un segundo corpus de consulta corresponde a documentos del Fondo de la Real Audiencia recopilados por Contreras Seitz (inédito). Se trata principalmente de documentos judiciales del siglo xVII y XVIII, los que, como hemos señalado antes (ver punto 2.3), son de gran interés para nuestro proyecto, pues incluyen juicios, los que son representativos de eventos comunicativos desarrollados en el lenguaje oral y por ende poseen características interaccionales reproducidas por el acto de escribanía a través del discurso referido.

Por este mismo motivo, y dado que el objeto de estudio de la presente propuesta se enmarca dentro del ámbito de los tratamientos, no consideraremos algunos corpus reconocidos en Chile, tales como Documentos inéditos para la historia de Chile (Medina 1888-1902) o Testamentos coloniales chilenos (Kordic 2005); el primero, porque es una obra de transcripción moderna que imposibilita el análisis lingüístico a nivel morfosintáctico, y el segundo, puesto que, si bien de edición filológica, se basa en una tipología textual que se aleja demasiado del plano lingüístico de la interacción.

Nuestro tercer corpus lo constituyen dos obras de edición filológica: el Epistolario de Sor Dolores Peña y Lillo (Chile, 1763-1769) (Kordic 2008) y la Relación Autobiográfica de Úrsula Suárez (1666-1749) (Ferrecio 1984). Pese a que esta última ya ha sido estudiada, consideramos relevante llevar a cabo un nuevo análisis, dado que nuestros planteamientos cuantitativos y cualitativos son diferentes a los abordados previamente. Conviene resaltar que en ambos casos las obras remiten a muestras de habla vernácula, espontánea y natural que nos acercan a la vida cotidiana en convento de dos mujeres representativas de la clase chilena alta (Úrsula Suárez) y baja (Dolores Peña y Lillo) de los siglos xviı y xvıII.

En concordancia con los corpus descritos hasta aquí -y según lo señalado en apartados anteriores- queda en evidencia la necesidad de acudir a un mayor número de documentos privados, en general, y de textos representativos de situaciones comunicativas de tipo más apelativo, para lo cual se planea realizar una revisión exhaustiva de los Fondos Históricos del Archivo Nacional, lo que permitirá generar un cuarto corpus de consulta.

\subsection{Análisis}

El análisis que proponemos en este estudio considera la evaluación de varios factores, tanto lingüísticos como extralingüísticos:

a) Morfosintaxis: siguiendo propuestas validadas en estudios previos (Fontanella de Weinberg 1999, Bentivoglio 2002-2004) el nivel gramatical incluye análisis de patrones de combinación según función sintáctica (como pronombre sujeto, formas pronominales tónicas y átonas, adjetivos y pronombres posesivos, ocurrencias verbales) y orden oracional.

b) Relación pragmática entre interlocutores de un evento comunicativo in 
situ (representada a través del acto de escribanía en textos de tipo judicial o notarial) o por la relación entre el autor de un documento y el/los receptor(es) de este.

c) Tipología discursiva, para lo cual se consideran textos de tipo descriptivo, narrativo y argumentativo, según se trate de la categoría predominante o de la combinación entre estas; asimismo, se examinan las funciones textuales (primarias y secundarias) tales como informar, solicitar, autorizar, etc. de acuerdo a la temática del documento.

d) Ámbito de uso del documento, el cual puede ser público o privado, como hemos explicado anteriormente (sección 2.3)

e) Nivel de formalidad (formal, semi-formal, informal), extraído principalmente a partir de los rasgos $(b)$ y (d).

f) Formación cultural/educacional de los autores de los documentos, para lo cual se realizará un rastreo histórico sobre la educación de los autores de los documentos.

A continuación presentamos resultados preliminares sobre la base de un corpus exploratorio en el que hemos analizado la relación entre el uso de las formas de tratamiento y cinco de las seis variables recién expuestas, entre las que destaca la evaluación de aspectos lingüísticos (rasgos morfosintácticos) y pragmático-discursivos (relación entre interlocutores, tipología discursiva, ámbito de uso y nivel de formalidad).

\section{RESULTADOS PRELIMINARES}

En esta sección presentamos resultados obtenidos a partir de la aplicación de nuestra propuesta de análisis sobre un corpus exploratorio compuesto de once documentos del siglo XVII, extraídos desde el volumen II de Memoria documental (Contreras Seitz y Salvo, 2013). En concreto, se trata de ocho documentos públicos y tres documentos privados ${ }^{6}$, que datan desde el año 1605 al 1696 en los cuales se registran seis formas de tratamiento, entre las que destaca la construcción del posesivo vuestra (o $s u)+$ sustantivo abstracto + 3a persona singular.

\footnotetext{
$6 \quad$ En este punto no fue posible realizar un muestreo al azar, ya que se trata de los únicos tres documentos privados incluidos en la obra.
} 
Tabla 2. Formas de tratamiento en el siglo XVII

\begin{tabular}{|c|c|}
\hline Forma de tratamiento & Ocurrencia \\
\hline vuestra merçed & 45 \\
\hline vuestra magestad & 28 \\
\hline vuestra alteza/altesa & 10 \\
\hline vuestra sseñoria & 6 \\
\hline su merçed & 1 \\
\hline vos & 1 \\
\hline Total & 91 \\
\hline
\end{tabular}

Estudios previos corroboran el empleo de estas estructuras desde el siglo XV como "fórmulas honoríficas, de uso muy especializado y reglamentado (en función del cargo del destinatario), propias del estilo administrativo solemne de la época, esto es, del característico de documentos públicos, cartas oficiales o discursos cortesanos". (Calderón Campos 2003: s.p.). Por un lado, desde el punto de vista cuantitativo y tal como se observa en la tabla 2, la forma nominal más frecuente es vuestra merçed, la cual se emplea en documentos públicos y privados, a diferencia de los usos reverenciales propios del tratamiento hacia el rey, vuestra magestad, u otras autoridades, como vuestra altezalaltesa o vuestra sseñoria, las que se utilizan únicamente en el ámbito público. Las formas menos frecuentes corresponden a su merçed y vos, las que tienen como característica el aparecer contextualmente después de otra forma de tratamiento. En el primer caso, se trata de un tratamiento que sigue a vuestra merçed:

(2) Remitio el darmela a Vuestra. merçed. - $\$$ / A quien suplico. se sirua de nombrar escriuano para la dicha / posesión y darmela sigun y de la manera que en el titulo / original que presento con la dicha comision se contiene y / pido Justisia / gonçalo / bezerra [firmado] $\$$ / [letra de Luis de Medina] La presento el sobredicho y por su merçed vista y el dicho titulo / y comision dijo que la acetaua y açeto y esta presto de dar la / dicha posesión en el dicho lugar segun y como en el dicho ti / tulo se contiene y que se ponga ynserte con este proueymi / ento y questa presto de hacer el dicho nonbramiento des / criuano y asi lo proueyo y firmo de su nonbre el dicho / dia mes y año / don jorje delga / dillo barba [firmado] ante mi / luis de + medina [firmado] / escribano nom [brado]

Lo relevante en este tipo de estudios es que en un mismo documento puede haber más de una 'voz', en el sentido en que muchas veces los textos son producidos por dos o más 
autores, pues como ocurre en el caso de los textos públicos oficiales -notariales o jurídicospueden intervenir tanto escribanos como interlocutores presentes en el acto comunicativo, quienes son generalmente los involucrados directos. Así pues, en el ejemplo (2) se observa cómo el involucrado directo, Gonzalo Becerra, se dirige a una autoridad (en el documento, Jorge Delgadillo) a través de vuestra merçed para realizar una solicitud de posesión de tierras -acto que es transcrito por el escribano Luis de Medina- la cual es respondida por Delgadillo, quien trata a Becerra de su merçed.

Una situación similar ocurre con vos, forma pronominal que se da únicamente en un documento del año 1676 en el cual se solicita traspaso de tierras, encontrándose presente en el acto los dos interlocutores involucrados en la cesión y entrega de terrenos y la autoridad competente. El solicitante se dirige a la autoridad mediante la fórmula nominal vuestra sseñoria, quien a su vez resuelve y responde a este mediante vos (y sus formas verbales), haciendo alusión a una situación de estatus asimétrica que es reproducida textualmente en el acto de escribanía.

(3) El Capitan Don Thomas de Sotomayor que sírue / de reformado serca de la persona de Vuestra sseñoria. díze que â mas tiempo de / veinte y tres años a que sírue a su Magestad. en la Guerra de este Reíno / y en dicho tiempo los señores Gouernadores antesesores de Vuestra sseñoria. An eçhado / mano de su persona para cosas que an ymportado para la quietud y so / siego de este Reino [...] para / remedio de lo qual a Vuestra sseñoria. pide y suplica se sirua de hazerle / merçed de las mil y quinientas quadras de tierras con las de / maçías que vbiere debajo de los linderos. en que rezeuíra vien / y merçed de la Grandeza de Vuestra sseñoria. [...] Lorenzo Sançhez de Guzm[an] / Dezicíon En cuya conzideraçion por el presente en nombre de su Magestad. [que] / Dios guarde. como su Gouernador. y Capitan general. hago merçed a vos el dicho / Don Thomas de Sotomayor. de las mil y quinientas quadras de ti[erras] / contenidas en los recaudos de suso ynzertos segun y de [la] / manera que las pedis para que las ayaís tengais y poseaís / y vuestro herederos y subçesores y quien de ellos tuviera[las] / y las podreis vender donar trocar o cambiar a quien os pareçi[ere] /

Por otro lado, desde un punto de vista morfosintáctico se observa que es común el empleo de las formas de tratamiento como término de proposición (seguidas de $a$, ante, con, de, para), cuya frecuencia de uso es mucho más elevada ( 67 ocurrencias) que en la función de sujeto ( 24 ocurrencias), el cual, además, suele ir en posición postverbal:

(4) a. a Vuestra Alteza Pido y suplico mande con / Breuedad. determinar la dicha causa

b. no quedara bien si no diera [cum] / plimiento al precepto yncintiuado / en los demas que se ofrecieren Nuebamen[te] / del hagrado de Vuestra merced 
c. Los dichos padres quando se pierda todo. no pier / den nada. Y quando se gane todo. no a de gana[r] / nada Vuestra Magestad porque se an de lleuar honrra y pro[ve] / cho

d. Si se pierde El rreyno. No podra aberi / guar Vuestra magestad. quien fue causa del daño.

En el plano discursivo se registran variaciones en función del tipo de documento y la temática. De esta forma, las temáticas en las que se realiza alguna solitud o petición presentan mayores índices apelativos, y por ende, mayor frecuencia de uso de formas de tratamiento (a excepción de un documento del año 1614 en el cual se le informa al rey de una situación particular, a quien no obstante se representa como persona perjudicada de los hechos, lo cual motiva el empleo del apelativo). Lo anterior se ilustra en la tabla 3, en la que se incluye la distribución de las formas de tratamiento según factores discursivos como género y tipo de texto.

\begin{tabular}{|c|c|c|c|c|}
\hline \multicolumn{5}{|c|}{ Tabla 3. Formas de tratamiento según género y tipo textual } \\
\hline \multirow{2}{*}{ Ámbito uso } & Género & Tipo texto & Forma tratamiento & Frec. uso \\
\hline \multirow{3}{*}{ Público } & & & vuestra magestad & 28 \\
& Carta oficial & Argumentativo & vuestra alteza/altesa & 10 \\
& Acta judicial & Descriptivo & vuestra sseñoria & 6 \\
& Acta notarial & Informativo & vuestra merçed & 3 \\
& & & su merçed & 1 \\
& & & vos & 1 \\
\hline \multirow{2}{*}{ Privado } & Carta personal & Descriptivo & vuestra merçed & 42 \\
& & Informativo & & \\
\hline
\end{tabular}

En donde se observa que el ámbito público presenta mayor variación en el empleo de tratamientos pronominales, los que sin embargo se corresponden con usos estandarizados de la época para usos apelativos hacia autoridades oficiales o reales. En cuanto a géneros textuales, en nuestro corpus figuran documentos de actas (generalmente con la participación de varios interlocutores) y cartas oficiales al rey o autoridades. En dichos géneros la tipología textual suele manifestar combinaciones que abarcan desde una descripción pormenorizada de determinados hechos o circunstancias, en cuyo caso también cumplen una función informativa, hasta pasar a planteamientos de solicitudes o peticiones, para lo cual se requiere justificar mediante el uso de argumentación.

Es por esta misma razón que por lo general no se trata de categorías exclusivas, sino de la confluencia de varias tipologías. Lo mismo sucede en el ámbito privado, cuyo género 
corresponde a cartas personales en las que se combinan tipologías descriptivo-informativas en temáticas que a veces pueden terminar en solicitudes especiales (como realizar un trámite, por ejemplo). A nivel estructural, cabe mencionar que las cartas personales se caracterizan por presentar un sistema de apertura más apelativo en torno al plano afectivo, como consta en los tres documentos privados de finales del periodo:

(5) a. Señor mío y mí Amígo Deuen de ser los / embarasos de Vuestra merçed muí grandes respecto de que / viénen repétidos correos y no me traen carta. b. Muy señora mia muchos Días â, que me man / tengo sin Letras de Vuestra merçed, solo con las no / ticias que adquiero de La buena salud que / a Vuestra merçed, deseo

c. Señor mio y mi Primo. estrañara Vuestra merçed / mucho y con rason el Ver mis letras / quando no lo e echo otra ves acudiendo / a Vna obligasion tan de Justisia

En dichos documentos se corrobora, además, que, inmediatamente después de la apelación inicial, se inserta la forma de tratamiento vuestra merçed, exclusiva de este ámbito, por lo menos en el trato entre amigos (5a), de marido a mujer (5b) y de prima a primo (5c). En cuanto a la estructura de cierre, se siguen las pautas de 'pedir a Dios por la salud' del receptor de la misiva y 'besar las manos', como muestra de cortesía:

(6) a. Nuestro señor guarde a Vuestra merçed muchos años Concepçion y / febrero 12 de 1695 / Besa las manos de Vuestra merçed Su seguro servidor y amigo / don Juan VrrisPurro

b. Cuia Perssona guarde nuestro señor Como deseo Y merese [...] / y henero 10 de 1696 / Muy. Señora. Mia / Besa Las Manos de Vuestra merçed su ma[yor] / oVligado serVidor / Martin Gonzalez / De la cruz

c. Señor. mio / Besa.Las.Manos. de Vuestra merçed su prima / y rendida servidora / Dońa Josepha cortes / y monrroi

Por último, con respecto a la dimensión pragmática se observan las siguientes relaciones y funciones asociadas al empleo de las formas de tratamiento: 
Tabla 4. Formas de tratamiento según factores pragmáticos y estilísticos

\begin{tabular}{|c|c|c|}
\hline Forma tratamiento & Tipo de relación-Registro & Función \\
\hline \multirow{2}{*}{ vuestra merçed } & asimétrica-formal & Respeto $>$ autoridad \\
\cline { 2 - 3 } & simétrica-semiformal & Respeto $>$ familiar cercano, amistad \\
\hline vuestra magestad & asimétrica-formal & Respeto $>$ autoridad real \\
\hline vuestra alteza/altesa & asimétrica-formal & Respeto $>$ autoridad \\
\hline vuestra sseńoria & asimétrica-formal & Respeto $>$ autoridad \\
\hline su merced & asimétrica-formal & Respeto $>$ inferior \\
\hline vos & asimétrica-formal & Respeto $>$ inferior \\
\hline
\end{tabular}

El corpus exploratorio analizado permite evidenciar, por un lado, que la función principal que se extrae del uso apelativo está asociada al valor de respeto o cortesía, el que varía en grados según se trate de una figura real, para el cual se emplea únicamente vuestra magestad, mientras que el trato hacia la autoridad, en cualquier estatus público, varía entre vuestra altezalaltesa, vuestra sseñoria y vuestra merçed. Por su parte, se registra igualmente la utilización de su merçed en el trato de una autoridad hacia un interlocutor inferior en calidad de solicitante. El uso de vos se emplea de manera similar, de autoridad hacia inferior. Se constata, por lo tanto, que esta forma de tratamiento pronominal aún se empleaba en la norma culta en este periodo.

Por otro lado, el análisis de los documentos del ámbito privado demuestra que el empleo de vuestra merçed es extendido y aplicable a relaciones simétricas, como las que se dan entre familiares cercanos y amistades.

\section{DisCUSIÓN Y CONCLUSIONES}

El estudio de las formas de tratamiento en el español de Chile es una temática que en los últimos ańos se ha ido desarrollando progresivamente desde perspectivas principalmente sociolingüísticas. No obstante, el ámbito diacrónico o histórico ha sido escasamente abordado (Avilés 1993, Araya 1995, Sweeney 2013, Newall 2007). En este sentido, la presente propuesta pretende llenar un vacío epistemológico, en tanto hasta la fecha no se ha llevado a cabo ninguna investigación en la que se analice el desarrollo de las formas de tratamiento en un periodo de tiempo amplio y tomando como base un corpus de estudio fiable y representativo. Otro aspecto importante que se releva es la inclusión de un análisis variacionista basado en una visión integral del objeto de estudio, en el que se examinan variables en distintos niveles de la lengua -gramática, pragmática y discurso- y 
factores extralingüísticos, como el estilo o grado de formalidad de la situación comunicativa y la formación cultural de los autores de los documentos (también conocido como 'nivel de instrucción', en la clásica terminología sociolingüística).

De esta forma, en el presente trabajo hemos esbozado la problemática y hemos propuesto un nuevo enfoque metodológico, el cual hemos aplicado preliminarmente sobre una muestra exploratoria de documentos públicos y privados del siglo xviI (Contreras y Salvo 2013), periodo de vital importancia que se entrecruza en dos momentos de la historia del español de Chile que Cartagena (2002b) denomina periodo fundacional (1541-1650) y consolidación de la variedad lingüistica y sociedad coloniales (1650-1750) (p. 56-58). Situando nuestro análisis en este contexto socio-histórico, se comprueba la co-ocurrencia de al menos seis formas de tratamiento: vuestra merçed, vuestra magestad, vuestra altezalaltesa, vuestra sseñoria, su merced y vos.

Si nos ceñimos a un criterio cuantitativo, queda en evidencia la alta frecuencia de uso de vuestra merçed, forma que además presenta una gran extensión, tanto en los ámbitos público como privado, en registros formales y semiformales, demostrando así que se trataba de la "fórmula de respeto por excelencia" avanzado el siglo XviI (Lapesa 1981, Alvar y Pottier 1987, citado en Rivadeneira 2009: 47), uso que probablemente arrastra ya desde el s. Xvi: "vuestra merced se utiliza [...] para las relaciones formales simétricas entre nobles y para las relaciones asimétricas nobiliarias de inferior a superior" (Calderón Campos 2003: s.p.). Paralelamente, las formas vuestra magestad, vuestra altezalaltesa y vuestra sseñoria presentan un uso condicionado principalmente por el factor pragmático, en tanto se emplean únicamente en el trato deferencial hacia el rey y autoridades en general en documentos oficiales. Por su parte, el empleo de vos, que combina morfosintácticamente con formas verbales de voseo diptongado y pronombre átono respectivo (os), se evidencia como trato cortés hacia un interlocutor de menor estatus social. Cabe mencionar que el uso de voseo ya se encuentra estigmatizado en este periodo de tiempo en el espańol peninsular (Pla Cárceles 1923, Lapesa 1968, Rini 1996), norma que aún no parece propagarse hacia el español americano, pues se evidencia en documentos epistolares de otras regiones colonizadas del siglo XVI (Bentivoglio 2002-2004, Calderón Campos 2003) y XVII (Díaz Collazos 2015).

Para finalizar, quisiéramos recalcar el hecho de que nos encontramos en la actualidad ante una situación bastante laboriosa en comparación con otras variedades del español, como la argentina (Fontanella de Weinberg 1971, 1987; Rigatuso 1986, 1988-1989, 1992, 1993; Rojas 1988-1989, 1992, 1997), uruguaya (Bertolotti 2001, 2004, 2011, 2012), colombiana (Díaz Campos 2015) y costarricense (Quesada Pacheco 1988, 2006, 2010) en donde se han efectuado grandes proyectos de investigación en el ámbito de historia de la lengua y de las formas de tratamiento, específicamente. Por este motivo, realizar un estudio de este tipo contribuye no solo a generar mayor conocimiento sobre los orígenes del español chileno, sino que además permite indagar los procesos de cambio lingüístico y la manera en que estos se proyectan en un continuum temporal como reflejo de modificaciones en el sistema sociocultural, en un área dialectal que presenta rasgos propios y distintivos dentro del mundo hispanohablante (Ĉerný 1999, Benavides 2003). 


\section{Agradecimientos}

Los autores de este trabajo agradecen el financiamiento de Conicyt a través del proyecto Fondecyt Regular $N^{\circ} 1171031$. La primera autora agradece, asimismo, a Eliana Valenzuela y Marcelo Rivadeneira por su constante apoyo y motivación y a Erico, Montserrat y Marshall Carmona por toda la ayuda prestada durante la realización de esta investigación.

\section{Obras Citadas}

Alvar, M. y Pottier, B. (1987). Morfología histórica del español. Madrid: Gredos.

Álvarez Nazario, M. (1991). Historia de la lengua española en Puerto Rico. Santo Domingo: Academia Puertorriqueña de la Lengua Española.

Araya, A. (1995). "Variaciones sociolingüísticas del voseo en la Relación Autobiográfica de Úrsula Suárez (1666-1749)". En Perdiguero, H. \& Álvarez, A. (Eds.), Estudios sobre el español de América, Proceedings of the $V$ Congreso Internacional de El Español de América, Burgos.

Avilés, P. (1993). "Fórmulas de tratamiento pronominales de segunda persona de singular en la Relación autobiográfica de Úrsula Suárez". Taller de Letras, 21: 25-36.

Bello, A. (1951) [1834]. "Advertencias sobre el uso de la lengua castellana dirigidas a los padres de familia, profesores de los colegios y maestros de escuela”. En Bello, Andrés, Obras completas, Estudios gramaticales, vol. V. Caracas: Ediciones del Ministerio de Educación [ $1^{\text {a }}$ edición Santiago de Chile: Imprenta de P. Ramírez].

Bello, A. (1883). Gramática de la lengua castellana destinada al uso de los americanos. En Obras completas de don Andrés Bello, vol. IV. Santiago de Chile: Imprenta de Pedro G. Ramírez.

Benavides, C. (2003). “La distribución del voseo en Hispanoamérica”. Hispania 86(3), 612-23.

Bentivoglio, P. (2002-2004). "Formas de tratamiento en cartas de la segunda mitad del siglo XVI: una aproximación pragmática”. Archivo de Filología Aragonesa 59-60(1), 229-248.

Bertolotti, V. (2004). “Tuteo y voseo en el Uruguay durante el siglo xIX”. Actas del III Congreso Brasileiro de Hispanistas, Universidade Federal de Santa Catarina, Florianopolis.

Bertolotti, V. (2011). Los cambios en la segunda persona del singular durante el siglo XIX en el español del Uruguay. Tesis doctoral, Universidad Nacional de Rosario.

Bertolotti, V. (2012). "Claves para la historia del español en el Río de la Plata: avances y rectificaciones sobre el tuteo y el voseo". Revista de la Sociedad Argentina de Lingüistica, 7-26.

Bertolotti, V. \& Coll, M. (2001). "Los cambios de las formas de tratamiento en la ruptura del orden colonial: un aporte a la historia de la lengua espańola en el Uruguay". En Frega, A. \& Islas, A. (Eds.). Nuevas miradas y debates en torno al Artiguismo. (pp. 211234). Montevideo: Departamento de Publicaciones de la Facultad de Humanidades 
y Ciencias de la Educación.

Brown, R., Gilman, A. (1960). "The pronouns of power and solidarity". En Sebeok, T. (ed.), Style in language, Cambridge, MA. / New York: The MIT Press: 253-276.

Calderón Campos, Miguel. (2003). "Fórmulas de tratamiento en las cartas del conde de Tendilla (1504-1506)". Tonos digital, Revista electrónica de estudios filológicos, 5. Disponible en >https://www.um.es/tonosdigital/znum5/estudios/C-Tendilla.htm.

Carricaburo, N. (1997). Las fórmulas de tratamiento en el español actual. Madrid: Arco/ Libros.

Carricaburo, N. (2004). "El voseo en la Historia y en la lengua de hoy". Disponible en http://www.elcastellano.org/ns/edicion/2004/julio/voseo.html.

Cartagena, N. (2001). "Conservación y variación como factores de divergencia del verbo español en América. Posibilidades y límites de convergencias normativas". Actas del Congreso Internacional de la lengua española, El español en la sociedad de la información, Valladolid, 16-19 oct. Disponible en http://www.congresosdelalengua.es

Cartagena, N. (2002a). "Algunos aspectos de la lengua de la Relación autobiográfica de la monja chilena Úrsula Suárez (1666-1749)". Mapocho, Revista de Humanidades, 52, 55-62.

Cartagena, N. (2002b). Apuntes para la historia del español de Chile. Cuadernos de la Academia Chilena de la Lengua. Santiago de Chile: Ediciones Rumbos.

Ĉerný, J. (1999). "Observaciones sobre el español hablado en América". Iberoamericana Olomucensia I, Romanica Olomucensia VIII, Philologica 74, 39-48.

Contreras Seitz, M. (2009a). "Bases para un estudio de la sintaxis histórica del español de Chile”. Estudios Filológicos, 44: 27-51.

Contreras Seitz, M. (2009b). "Hacia la constitución de un corpus diacrónico del español de Chile". Revista de Lingüistica Teórica y Aplicada 47(2), 111-134.

Contreras Seitz, M., Salvo, M., Molina, R. \& Jara, R. (2013). Memoria documental en textos chilenos del periodo colonial. Edición semidiplomática siglos XVI (vol. 1), XVII (vol. 2) y XVIII (vol. 3). Saarbrücken: Editorial Académica Española.

De Mauro, T. (1970). "Tra Thamus y Teuth. Note sulla norma parlata e scritta formale e informale nella produzione e realizzazione dei Segni linguistici”. En Lingua parlata e lingua scritta (167-179). Palermo: Centro de Studi Filologici e Linguistici Siciliani.

Díaz Collazos, Ana María. (2015). Desarrollo sociolingüístico del voseo en la región andina de Colombia (1555-1976). Berlin/Boston: Walter de Gruyter.

Durante, L. (1996). Diplomática. Usos nuevos para una antigua ciencia. Colección Biblioteca Archivística. Carmona: S\&C Ediciones.

Ferreccio, M. \& Rodríguez, M. (1984). Úrsula Suárez (1666-1749). Relación autobiográfica. Santiago de Chile: Biblioteca Antigua Chilena.

Fontanella de Weinberg, M. (1971). "El voseo en Buenos Aires en las dos primeras décadas del siglo xIx". Thesaurus, 26(3), 495-514.

Fontanella de Weinberg, M. (1987). El español bonaerense, cuatro siglos de evolución lingüistica, 1580-1980. Buenos Aires: Hachette.

Fontanella de Weinberg, M. (1989). "Avances y rectificaciones en el estudio del voseo ame- 
ricano". Thesaurus, 44(3), 521-525.

Fontanella de Weinber, M. (1994). "Fórmulas de tratamiento en el español americano (siglos XVI y XVII)”. En Fontanella de Weinberg, María Beatriz (comp.), El español en el Nuevo Mundo: estudios sobre historia lingüistica hispanoamericana (pp. 7-31). Oea/ Oas, Interamer.

Fontanella de Weinberg, M. (1995-1996). "Los sistemas pronominales de segunda persona en el mundo hispánico". Homenaje a Rodolfo Oroz. Boletín de Filología de la Universidad de Chile, 35, 151-162.

Fontanella de Weinberg, M. (1999). "Sistemas pronominales de tratamiento usados en el mundo hispánico”. En Bosque I. y Demonte V. (Eds.), Gramática descriptiva de la lengua española, 1 (pp. 1399-1425). Madrid: Real Academia Espańola/Espasa Calpe.

Fuenzalida Grandón, A. (1903). Historia del desarrollo intelectual en Chile (1541-1810). Santiago de Chile: Imprenta Universitaria.

Frago, J. A. (2010). "Sobre el español de Chile: del periodo colonial al independiente". Boletin de Filología 45(1): 103-126.

Frontaura, J.M. (1892). Noticias históricas sobre las escuelas públicas de Chile a fines de la era colonial. Santiago de Chile: Imprenta Nacional.

García, E. (1994). "Una casilla vacía en el paradigma pronominal del voseo: convusco". En Lüdtke, Jens (comp.), El español de América en el siglo XVI. Actas del Simposio del Instituto Ibero-Americano de Berlín, 23 y 24 de abril de 1992 (pp. 13-38), Frankfurt am Main: Vervuert.

García Mouton, P. (1999). “Tratamientos en las cartas de Indias”. En Amparo Morales et al. (eds.), Estudios de lingüistica hispánica. Homenaje a María Vaquero (pp. 263-276). San Juan: Editorial de la Universidad de Puerto Rico.

Garrido, A. (1992). Los orígenes del español de América. Madrid: Mapfre.

Henríquez Ureña, P. (1921). "Observaciones sobre el español de América”. Revista de Filología Española 8: 357-390.

Hummel, M., Kluge, B. \& Vázquez-Laslop, M. (2010). Formas y fórmulas de tratamiento en el mundo hispánico. México, D.F.: El Colegio de México/Graz, Austria: KarlFranzens-Universität.

Kany, C. (1969) [1945]. Sintaxis hispanoamericana. Madrid: Gredos.

Kordić, R. (2005). Testamentos coloniales chilenos. Madrid: Universidad de Navarra, Iberoamericana/Vervuert.

Kordić, R. (2008). Epistolario de Sor Dolores Peña y Lillo (Chile, 1763-1769). Madrid: Universidad de Navarra, Iberoamericana/Vervuert.

Labarca, A. (1939). Historia de la enseñanza en Chile. Santiago de Chile: Imprenta Universitaria.

Lapesa. R. (1968). "Las formas verbales de segunda persona y los orígenes del 'voseo"”. Asociación Internacional de Hispanistas, Actas III, 519-531.

Lapesa, R. (1970a). "Personas gramaticales y tratamientos en español". Revista de la Universidad de Madrid (Homenaje a Menéndez Pidal, IV), 19, 141-167. 
Lapesa, R. (1970b). “Las formas verbales de segunda persona y los orígenes del voseo”. En Magis, Carlos (ed.). Actas del III Congreso Internacional de Hispanistas, México: El Colegio de México: 519-531.

Lapesa, R. (1981). Historia de la lengua española. Madrid: Gredos.

Lenz, R. (1940). "Estudios chilenos. Fonética del castellano de Chile”. BDH, 6, El español en Chile. Trabajos de Rodolfo Lenz, Andrés Bello y Rodolfo Oroz. Buenos Aires: Universidad de Buenos Aires.

Llorente, A. (1965). "Algunas características lingüísticas de La Rioja en el marco de las hablas del valle del Ebro y de las comarcas vecinas de Castilla y Vasconia". Revista de Filología Española 5: 321-350.

Medina, J. B. (1888-1902). Colección de documentos inéditos para la historia de Chile: desde el viaje de Magallanes hasta la batalla de Maipo: 1518-1818. Santiago: Imprenta Ercilla, 30 vols.

Medina, J. T. (1905). La instrucción pública en Chile, desde sus orígenes hasta la fundación de la Universidad de San Felipe. Santiago: Imprenta Elzeviriana.

Medina, A. y Méndez, C. (2011). "El corpus histórico del español en México". Revista Digital Universitaria, vol. 12, no 7.

Medina Morales, Francisca. (2005). "Problemas metodológicos de la sociolingüística histórica”. Forma y Función 18: 115-137.

Medina Morales, F. (2010). "La metodología en los estudios sobre formas y fórmulas de tratamiento en español”. En M. Hummel, B. Kluge \& M. E. Vázquez (Eds.), Formas y fórmulas de tratamiento en el mundo hispánico (pp. 21-56). México, D.F.: El Colegio de México/Graz, Austria: Karl-Franzens-Universität.

Michele de Oliveira, S. (2010). "La integración de la teoría y la metodología como desencadenante de un nuevo modelo de formas y fórmulas del tratamiento". En M. Hummel, B. Kluge \& M. E. Vázquez (Eds.), Formas y fórmulas de tratamiento en el mundo hispánico (pp. 57-77). México, D.F.: El Colegio de México/Graz, Austria: Karl-Franzens-Universität.

Morín Rodríguez, A. (2001). Las formas pronominales de tratamiento en el español de Las Palmas de Gran Canaria: variación y actitudes lingüisticas. Granada: Método Ediciones.

Moser, K. (2010). "Las formas de tratamiento verbales-pronominales en Guatemala, El Salvador, Panamá (y Costa Rica): hacia una nueva sistematización en la periferia centroamericana”. En M. Hummel, B. Kluge \& M. E. Vázquez (Eds.), Formas y fórmulas de tratamiento en el mundo hispánico (pp. 271-291). México, D.F.: El Colegio de México/Graz, Austria: Karl-Franzens-Universität.

Newall, G. (2007). "The loss of the voseo in Chilean Spanish: Evidence in Literature”. Working Papers in Linguistics, 13(2), 164-178.

Pla Cárceles, J. (1923). “La evolución del tratamiento 'vuestra merced”". Revista de Filología Española 10, 3: 245-280.

Oesterreicher, W. (1996). "Lo hablado en lo escrito. Reflexiones metodológicas y aproximación a una tipología”. En Thomas Kotschi et al. (eds.), El español hablado y la cultural 
oral en España e Hispanoamérica (pp. 317-340). Frankfurt am Main: Vervuert.

Oroz, R. (1966). La lengua castellana en Chile. Santiago: Universidad de Chile.

Otte, E. (1981). Cartas privadas de emigrantes a Indias (1540-1616). Sevilla: Junta de Andalucía.

Oyanedel, M. \& Samaniego, J. L. (1998-1999). "Notas para un nuevo perfil lingüístico del español de Santiago de Chile”. Homenaje al profesor Ambrosio Rabanales. Boletín de Filologia de la Universidad de Chile, 37 (pp. 899-913).

Penny, R. (1991). A history of the Spanish Language. Cambridge: Cambridge University Press.

Pérez Fernández, B. (1983). Historia de la escribanía en la Nueva España y el notariado en México. México: Instituto de Investigaciones Jurídicas/UNAM.

Quesada Pacheco, M. A. (1988). "Uso de las formas de tratamiento en cartas privadas escritas en América en el siglo xvi". Revista de Filología y Lingüistica de la Universidad de Costa Rica 14(2): 123-128.

Quesada Pacheco, M. A. (2006). “Formas de tratamiento en Costa Rica: visión histórica”. En Bustos Tovar, José, Girón Alconchel, José Luis (eds.), Actas del VI Congreso Internacional de Historia de la Lengua Española, vol. 3 (pp. 2323-2336). Madrid: Arco Libros.

Quesada Pacheco, M. A. (2010).”Formas de tratamiento en Costa Rica y su evolución (1561-2000)”. En M. Hummel, B. Kluge \& M. E. Vázquez (Eds.), Formas y fórmulas de tratamiento en el mundo hispánico (pp. 649-669). México, D.F.: El Colegio de México/Graz, Austria: Karl-Franzens-Universität.

Ramírez Luengo, J. L. (2003). “Contribución a la historia del voseo: El paradigma altoperuano a inicios del siglo XIX”. Estudios Filológicos, 38:179-188.

Real Academia Española. (2005). Diccionario Panhispánico de dudas.

Rigatuso, E. (1986). "Fórmulas de tratamiento en el español bonaerense de mediados del siglo XIX”. En Fontanella de Weinberg, M. (ed.), Aspectos de la historia del español de Argentina (pp. 71-123), Bahía Blanca: Universidad Nacional del Sur.

Rigatuso, E. (1988-1989). "Fórmulas de tratamiento sociales en el espańol bonaerense de mediados del siglo XIX". Cuadernos del Sur, 20-21: 65-93.

Rigatuso, E. (1992). Lengua, historia y sociedad. Evolución de las formas de tratamiento en el español bonaerense (1830-1930). Bahía Blanca: Departamento de Humanidades, Universidad Nacional del Sur.

Rigatuso, E. (1993). "Las fórmulas de tratamiento en la relación amorosa del español bonaerense: una visión diacrónica (1830-1930)". Anuario de Lingüistica Hispánica, 9: 257-287.

Rini, J. (1996). "The vocalic formation of the Spanish verbal suffixes -ais/-as, -eis/-es, -is, -ois/-os: A case of phonological or morphological change?" Iberoromania, 43-44, 1-16.

Rivadeneira, M. (2009). El voseo en medios de comunicación de Chile. Descripción y análisis de la variación dialectal y funcional. Tesis doctoral, Universitat Pompeu Fabra. ISBN: 9788469292648.

Rivadeneira, M. \& Clua, E. (2011). "Una visión desde el análisis de la variación dialectal y 
funcional en medios de comunicación”. Hispania, 94(4), 680-703.

Rivadeneira, M. (2016). "Sociolinguistic variation and change in Chilean voseo". En Moyna, Irene \& Rivera-Mills, Susana (eds.), Forms of address in the Spanish of the Americas. Amsterdam: John Benjamins, 87-118.

Rojas, M. E. (1985). Evolución histórica del español en Tucumán entre los siglos XVI y XIX". Tucumán: Universidad Nacional de Tucumán.

Rojas, M. E. (1988-1989). "Las formas pronominales de tratamiento en Tucumán, en la segunda mitad del siglo xix". Cuadernos del Sur, 21-22: 95-111.

Rojas, M. E. (1992). "Los primeros pobladores en Tucumán. Sus fórmulas de tratamiento", España y el Nuevo Mundo. Un diálogo de quinientos años. Buenos Aires: Academia Argentina de la Lengua.

Rojas, M. E. (1997). "Acerca del tratamiento referencial en los documentos coloniales del Río de la Plata". Lingüistica, 9: 125-134.

Rona, J. P. (1964). "El problema de la división del español americano en zonas dialectales". Presente y futuro de la lengua española, vol. 1 (pp. 215-226). Madrid: OFines.

Rona, J. P. (1967). Geografía y morfología del voseo. Pôrto Alegre: Pontíficia Universidades Católica do Rio Grande do Sul.

San Martín, A. y Guerrero, S. (2013). "Una aproximación sociolingüística al empleo del discurso referido en el corpus PRESEEA de Santiago de Chile". Signos 46(82): 258-282.

Saralegui, C. (1986). "Aproximación al voseo hispanoamericano". Revista del Instituto de Lengua y Cultura Españolas 2(2), 277-288.

Sweeney, P. (2013). El voseo en Chile: Factores histórico-morfológicos que explican su aparición y mantenimiento. USA: Outskirts Press.

St. Clair Sloan, A. (1922). "The pronouns of address in Don Quijote". The Romanic Review 13: 65-76.

Torrejón, A. (1986). "Acerca del voseo culto de Chile". Hispania 69(3), 677-683.

Torrejón, A. (1989). "Andrés Bello, Domingo Faustino Sarmiento y el castellano culto de Chile". Thesaurus 44(3): 534-558.

Torrejón, A. (2010a). "El voseo en Chile: Una aproximación diacrónica”. En M. Hummel, B. Kluge \& M. E. Vázquez (Eds.), Formas y fórmulas de tratamiento en el mundo hispánico (pp. 413-427). México, D.F.: El Colegio de México/Graz, Austria: KarlFranzens-Universität.

Vázquez Laslop. M. E. (2010). "Formas de tratamiento del español en México". En M. Hummel, B. Kluge \& M. E. Vázquez (Eds.), Formas y fórmulas de tratamiento en el mundo hispánico (pp. 247-269). México, D.F.: El Colegio de México/Graz, Austria: Karl-Franzens-Universität.

Wilson, W. (1940). "Él and ella as pronouns of address during the Golden Age". Hispania 23,4: 336-340.

Zamora, A. (1943). "Notas para el estudio del habla albaceteña". Revista de Filología Espanola 27: 233-255. 